\title{
Integrated Treatment of Mining Dam Wastewater With Quaternized Chitosan and Pan/hpmc/agno3 Nanostructured Hydrophylic Membranes
}

\author{
Rodrigo Gonçalves Bigogno ( $\sim$ bigogno@gmail.com ) \\ Marcos Lopes Dias \\ UFRJ: Universidade Federal do Rio de Janeiro \\ Mariana Borges N. Manhães \\ UENF: Universidade Estadual do Norte Fluminense Darcy Ribeiro \\ Ruben J. Sanchez Rodriguez \\ UENF: Universidade Estadual do Norte Fluminense Darcy Ribeiro
}

Universidade Estadual do Norte Fluminense Darcy Ribeiro https://orcid.org/0000-0002-8380-464X

\section{Research Article}

Keywords: Polymer membranes, Electrospinning, Polyacrylonitrile, Wastewater treatment, Water reuse

Posted Date: April 23rd, 2021

DOI: https://doi.org/10.21203/rs.3.rs-405694/v1

License: (c) (i) This work is licensed under a Creative Commons Attribution 4.0 International License. Read Full License

Version of Record: A version of this preprint was published at Journal of Polymers and the Environment on September 6th, 2021. See the published version at https://doi.org/10.1007/s10924-021-02273-5. 


\section{Abstract}

This study was developed a novel nanostructured membrane by electrospinning process, from polyacrylonitrile (PAN) modify by hydroxypropyl methylcellulose (HPMC) polymers containing $\mathrm{AgNO}_{3}$, to be used as a filter in an integrated wastewater dam treatment process to reuse it as drinking water. Different formulations (108 samples) were electrospun from PAN and $(0,5,10 \% \mathrm{w}) \mathrm{HPMC}$ and $(0,0.5,1 \% \mathrm{w})$ solutions to selected a more efficient formulation in water disinfection and higher hydrophilic character of the membrane to flow performance in the wastewater treatment. The PAN and HPMC phases in membranes were characterize by infrared spectroscopy (FTIR) and thermogravimetric analysis (TGA). The nanostructured membranes (SEM) were characterized by thickness fiber between $251 \pm 58$ and $306 \pm 49 \mathrm{~nm}$ and lower fiber/membrane volume relations. The presence of $\mathrm{HPMC}$ and $\mathrm{AgNO}_{3}$ in membrane formulation endows superhydrophilicity and permeability increase which up to $21,151 \pm 445 \mathrm{~L} \cdot \mathrm{m}^{-2} \cdot \mathrm{h}^{-1}$. After filtration process with PAN/HPMC/ $\mathrm{AgNO}_{3}$, all the tested water potability indexes were achieved. The primary treatment, using quaternized chitosan reduced the turbidity parameter from 19,000 NTU to 14 NTU, and after filtration with nanostructured membrane, to levels was below 1 NTU and pathogenic potential removed (Total Coliform and Escherichia coli). The results of this study indicated that the hydrophilic nanostructured membranes $\mathrm{PAN} / 10 \% \mathrm{HPMC} / 1 \% \mathrm{AgNO}_{3}$ have adequate properties to potential wastewater treatment mining for reuse. It's give a sustainable strategy for managing wastewater which should be reduce the volume of water in the tailing's dams and contributes to increasing the stability of dams and reducing risks with catastrophic environmental impact.

\section{Introduction}

Due to its high potential of environmental impacts and the repeated accidents of major proportions, the mining sector, in Brazil and worldwide, increasingly lives with socio-environmental conflicts. Dam failure has always been treated as a low-probability event, even though it displays potentially catastrophic effects. However, in the last 20 years the number of tailings dam ruptures has doubled worldwide [1]. Accidents such as the Gold and Copper tailings dam at Mount Polley in Canada in 2014 and the tailings dam at Xinta Mining Company, Shanxi, China in 2008, produced a huge spill of contaminated mud in Canada and the loss of approximately 277 people in China. In Brazil, the last major accidents occurred in less than 5 years. Samarco's accident in 2015 with 19 deaths and the release of 60 million $\mathrm{m}^{3}$ of tailings that contaminated $650 \mathrm{~km}$ of river until reaching the Atlantic Ocean, and Mineradora Vale's accident in the city of Brumadinho in 2019 with 275 deaths and 31 million $\mathrm{m}^{3}$ of tailings released $[2,3,4]$.

Among the main causes of tailings dam failures are infiltration, erosion, seismic liquefaction and excess water in the dam which causes overtopping [3]. Stability, monitoring, and risk management of a tailings dam is crucial to guarantee disaster control. Preventive actions such as controlling the volume of water present in the ore tailings which is stored in the reservoir of a dam shall contribute to reduce infiltration, erosion processes, pressure on the dam and the possibility of overtopping $[3,5]$.

Therefore, wastewater treatment stored in reservoirs and their subsequent reuse have been increasingly recognized as sustainable strategies to decrease stored water volume, thus contributing with the dam risks proper management. Water reuse has direct and positive relationship with its local availability, and it can be considered one of the current and essential strategies to enable new water sources for the industry, consequently translating itself into an immense added value concerning the environment and sustainable development [5]. 
The most relevant techniques for mining wastewater treatment use processes such as decantation basins, flotation, coagulation / flocculation / decantation to remove suspended solids and dissolved material. However, in order to reach potability standards for human consumption, filtration and disinfection technologies must be inserted in the process to retain bacteria, viruses and other suspended materials, thus ensuring this water is framed in specific drinking standards

Filtration by nanostructured membranes has been widely studied, due to its characteristic of being able to be modified, allowing the development of specific properties that allow its application in different areas and improving its performance, such as reduction of incrustations, removal of pollutants and disinfection capacity $[9,10,11]$. In membrane filtration, the filter medium is a thin synthetic material, which displays various thickness pores. Throughout this process, by applying pressure, water passes through the pores and the particles are physically trapped on the surface of the filtering material $[9,12]$. The pore structure is considered to be one of the most important properties of a membrane, as it can determine the filtration performance of the membrane. According to porosity, membranes can be classified into Microfiltration (MF), Ultrafiltration (UF), Reverse Osmosis (OR) and Nanofiltration (NF). These membrane filtration techniques can be used depending on specific characteristics, such as the type of water to be treated and according to the desired result of the treatment. In general, for the removal of larger particles, the MF and UF processes are used, for the removal of smaller particles and salts, the OR and NF techniques are used. Filtration of wastewater using nanostructured membrane technology is characterized by presenting high rejection rates, being able to filter particles between 0.0007-0.005 $\mu \mathrm{m}$. They exhibit several advantages, such as speed of water treatment, use of small construction areas, with compact plants, it presents easy automation potential and it enables future expansions through modules $[9,10,11,12]$.

Electrospinning is the spinning technique low-cost, able to synthesize materials in the form of fabrics with a certain strength and flexibility. Since these fiber's present characteristics such as high porosity, high specific surface area and spider web-like interconnected structure, electrospun nanostructured membranes are of great interest for application in wastewater treatment and recycling $[13,14,15,16]$. Electrospinning offers profuse benefits and presents itself as an innovative and practical method, due to its flexibility concerning membrane formulation, which can be easily functionalized by combining several modified polymers as well as appropriate morphologies to achieve various effects in water treatment $[17,18,19]$.

Performance of a membrane in the filtration process can be determined mainly by its permeability and impurities retention rate. Hydrophilicity, porosity and pore thickness are essential properties in the development of a nanostructured membrane for application in water filtration. The porosity and pore size of a filtering membrane directly influences the permeability and retention rate of the filter $[20,21]$ The combination of polymeric materials is widely used to achieve hydrophilic properties in membranes. Polyacrylonitrile (PAN) is one of the commonly used polymers for electrospinning, having the characteristic to produce ultrafine and homogeneous fibers. However, membranes from PAN exhibit a hydrophobic nature, which can reduce filtration performance. The wettability of the membrane surface depends on its structure and chemical nature. By modifying the chemical composition of the fiber through the insertion of hydrophilic components it is possible to change this property. The modification of PAN membranes through the incorporation of a polymer such as Hydroxypropylmethylcellulose (HPMC) and an additive such as $\mathrm{AgNO}_{3}$, it is possible to increase the wettability, which contributes to reduce the scale and improve the permeability of the membrane throughout the filtration $[14,22]$.

In the present work the main objective was the mining water reuse (considering the guidelines of the World Health Organization (WHO) for drinking water) using an integrated treatment process. In which quaternized chitosan was 
used as a coagulant and a nanostructured membrane obtained by electrospinning the polyacrylonitrile (PAN) and hydroxypropylmethylcellulose (HPMC) polymers containing $\mathrm{AgNO}_{3}$ was used for filtration.

\section{Materials And Methods}

\subsection{Preparation of PAN/HPMC/AgNO 3 precursor solutions by electrospinning process}

In an Erlenmeyer, PAN (Sigma-Aldrich Brazil Ltda) was dissolved in DMF (Sigma-Aldrich Brazil Ltda) in a weight ratio of 05:95. This solution was divided into 3 equal parts and, addition in respective part, 0,5 and 10\%w of HPMC (Sigma-Aldrich Brazil Ltda). After that, each solution was divided into 3 equal parts to addition $0,0.5$ and $1 \% \mathrm{~W}$ of $\mathrm{AgNO}_{3}$ (Sigma-Aldrich Brazil Ltda). Therefore, these 9 polymeric solutions with different percentages of HPMC and $\mathrm{AgNO}_{3}$ were stirred (500 rpm) under heating at $75^{\circ} \mathrm{C}$ for 3 hours, to obtaining homogeneous solutions [23].

\subsection{Preparation of nanostructured membrane}

The electrospinning of the solutions was performed using a device (Instor - Projects and Robotics, Brazil). The solutions were placed in a $5 \mathrm{~mL}$ disposable plastic syringe, equipped with a stainless-steel needle (N724-24G/2"/3, Hamilton) and horizontally connected to a flow control pump. The nanofibers were collected on a $100 \mathrm{~mm} \times 100 \mathrm{~mm}$ metal covered with aluminum foil Electrospinning was carried out with a relative humidity of (55 \pm 5$) \%$ at a temperature of $(20 \pm 1){ }^{\circ} \mathrm{C}$. [23, 24].

By crosslinking the inserted factors (Table 1), a total number of 108 samples was defined. The influence of electrospinning parameters (Flow rate, Tip-to-collector distance, Electrical field) and the addition of HPMC and $\mathrm{AgNO}_{3}$ on the morphology and mean fiber diameter of the was investigated [25]. The criterion used to establish the electrospinning parameters for each solution was the parameter that produced fibers with smaller mean diameter. Thus, from the experimental planning, a sample was chosen for the analyzed concentration. The fibers diameters were determined using the software SizeMeter, four SEM micrographs were analyzed for each membrane sample, and the diameters of 60 fibers ( 15 for each image) were measured and calculated at their average values.

Table 1 Experimental design for the electrospinning of the polyacrylonitrile nanofibers

\subsection{Nanostructured Membrane Characterization}

\subsubsection{Fourier Infrared Transform Spectroscopy (FTIR)}

The infrared spectra were recorded on a Shimadzu model IR Prestige-21 spectrophotometer. The spectra were obtained in the range between $400-4000 \mathrm{~cm}^{-1}$ accumulating 40 scans with resolution of $1 \mathrm{~cm}^{-1}$.

\subsubsection{Thermogravimetric Analysis (TGA/DTG)}

Thermogravimetric Analysis (TGA/DTG) were performed in a TGA Q5000 (Moldulated) TA Instruments. The samples $\left(12 \mathrm{mg}\right.$ ) were placed in Platinum-HT pan and heating rate $10.00^{\circ} \mathrm{C} / \mathrm{min}$ to $950.00^{\circ} \mathrm{C}$ in dynamic atmosphere of nitrogen $(50 \mathrm{~mL} / \mathrm{min})$.

\subsubsection{Scanning Electron Microscopy (SEM)}

The morphology of the electrospun membranes was investigated via scanning electron microscopy (SEM, JEOLJSM-6390-LV, 18 kV). Membrane images obtained by SEM were used to: 1) measure the fiber diameter of 108 
samples; 2) measure the thickness of the membranes through the image of the membranes cross section; and 3) analyze the membranes morphology before and after treatment wastewater.

\subsubsection{Porosity calculation}

The porosity of a fibrous membrane is characterized by the amount of empty spaces in its total volume [21]. The tests to assess the membranes porosity were carried out using samples of the membranes manufactured at nine different concentrations and their porosity was calculated using Eq. 1.

Porosity $(\%)=(\mathrm{V}-\mathrm{Vp} / \mathrm{V}) \times 100($ Ep. 1)

where,

$\mathrm{V}=$ Membrane total volume $\left(\mathrm{cm}^{3}\right)$

$\mathrm{Vp}=$ Fiber volume $\left(\mathrm{cm}^{3}\right)$

In order to assess the membrane volume, the samples were cut to the size of $(2 \mathrm{~cm} \times 2 \mathrm{~cm})$ corresponding to an area of $4 \mathrm{~cm}^{2}$. To obtain the thickness, the membranes were frozen in liquid nitrogen and fractured. The cross-sectional images of each membrane were obtained by SEM and measured using the SizeMeter software [26]. The volume occupied by the fibers was determined through the product of the mass by the relative density of each membrane. The samples were weighed and the relative density was calculated from the proportion of relative mass of each component (PAN $\left(1.184 \mathrm{~g} / \mathrm{cm}^{3}\right), \mathrm{HPMC}\left(1.26 \mathrm{~g} / \mathrm{cm}^{3}\right)$ and $\mathrm{AgNO}_{3}\left(4.35 \mathrm{~g} / \mathrm{cm}^{3}\right)$, considering the concentration of each sample. All procedures were performed three times for each sample, and then their average was reported.

\subsubsection{Determination of the degree of hydrophilicity by measuring the contact angle.}

The analysis of PAN membranes modified with $\mathrm{HPMC}$ and additive with $\mathrm{AgNO}_{3}$ was performed with the Sinterface equipment, model PAT-1M, operated at temperature of $(24 \pm 1){ }^{\circ} \mathrm{C}$ and using distilled water to form the drop $(8.8 \mu \mathrm{L})$ and limit time of experiment $60 \mathrm{~s}$.

\subsubsection{Permeability}

In the permeability study, the membranes were cut in circular shape with the aid of a template, their useful area was measured at $10.75 \mathrm{~cm}^{2}$, and inserted into the permeation cell on a porous support. Then, the cell was closed and connected to the system. The complete system consists of a feed tank of approximately 4 liters, a pressure gauge at the outlet of the permeation cell, a pressure regulating valve and a pump to allow recirculation of the feed solution. The system operates continuously, with concentrate and permeate recycling. Ultrapure water was used, and the pressure curve vs. permeate flow was obtained for operating pressures of $0.3 ; 0.4 ; 0.5$ bar for 1 hour. Three measurements of the permeate flow were performed for each of the defined pressures, and the results were obtained following Eq. 2 [27].

$J w=(V p / \Delta t . A m) \times 100$ (Eq. 2)

Where:

Jw = Permeate flow $\left(\right.$ L. $\left.\mathrm{m}^{-2} \cdot \mathrm{h}^{-1}\right)$; 
$\mathrm{Vp}=$ Permeate volume $(\mathrm{L})$;

$\Delta \mathrm{t}=$ Time $(\mathrm{h})$;

Am = Effective filtering area $\left(\mathrm{m}^{2}\right)$.

\subsection{Wastewater treatment}

\subsubsection{Primary treatment (S-Primary)}

With regard to the primary treatment process for bauxite tailings wastewater, it is subdivided into 03 stages, coagulation, flocculation and decantation (Fig. 1A) The analyses related to these steps were performed in according to the methodology described by in (previous) work [28]. Mining wastewater samples were subjected to primary treatment in a Jar Test equipment (Mod. 218/6, Nova Ética Comp. Ltda, Brazil), using as a coagulant, the biodegradable polymer quaternized chitosan. The treatment parameters were defined with a dosage of $5 \mathrm{mg} / \mathrm{L}$ of quaternized chitosan, rotation speed in the coagulation (fast mixing) $150 \mathrm{rpm}$ for $1 \mathrm{~min}, 40 \mathrm{rpm}$ for $10 \mathrm{~min}$ in the flocculation (slow mixing) and $0 \mathrm{rpm}$ for $20 \mathrm{~min}$ for decanting. After decanting the samples were collected $6 \mathrm{~cm}$ below the water surface in the jar.

Figure 1 Schematic representation of the experimental configuration of the integrated wastewater treatment system. (A) Primary treatment; (B) Membrane filtration, PI and FI are pressure and flowrate indicators, respectively

\subsubsection{Secondary wastewater treatment}

In order to evaluate the performance of electrospun membranes in reaching the potability parameters for water after primary treatment, the tests were carried out for nine models of membranes previously which were selected according to their fibers with smaller mean diameter among the 108 membranes defined in the experimental design (Table SI1).

A filtration (Fig. 1B) system made of stainless steel was used to carry out the analysis. With aid of a template, the membranes were cut and superimposed on a porous steel mesh that was coupled inside the equipment, which was closed. The water was inserted through one of the holes in the equipment in order to pass through the membrane and be collected through the other hole in the system. The filtered material samples were collected in specific bottles and identified. Three collections of 1 liter of filtered wastewater were performed for each membrane sample.

\subsubsection{Characterization of wastewater samples before and after treatments steps}

The wastewater samples were collected in 3 stages of the treatment process, at the CBA / Votoratim tailings dam (Mirai Mining Unit, Brazil), after the primary treatment process and after the secondary treatment (filtration). The parameters considered as performance indicators for treatment and control systems were analyzed. For samples collected in the three step phases of the process, analysis was carried out on 13 parameters and compared according to their limits established by the WHO Guidelines.

2.4.5. Analyses of Aluminum, Total Coliforms, Escherichia coli, Conductivity, Iron, Manganese, Dissolved oxygen, pH, Suspended Solids, Dissolved Solids and Turbidity of wastewater samples before and after treatments steps. 
The determination of Metals (Aluminum, iron, manganese) was performed: Digestion of $100 \mathrm{~mL}$ of sample with concentrated nitric acid and hydrochloric acid 1: 1 in a heating plate with a temperature not exceeding $90^{\circ} \mathrm{C}$. Bulk sample for $100 \mathrm{~mL}$ flask and taken to the measuring equipment. Equipment used: Optima 7300 DV ICP Spectrometer (ICP with Plasma flame). Equipment with validation and performance testing through Perkin Elmer. The determination of conductivity, dissolved oxygen and $\mathrm{pH}$ was performed from direct reading in the sample on electrodes for conductivity, dissolved oxygen and $\mathrm{pH}$ respectively. The equipment used was Digimed DM-32 Conductivometer with RBC calibration by Visomes, Digimed Oximeter with RBC calibration by Evagon and $\mathrm{pH}$ Meter Digimed DM-22 with RBC calibration by Visomes. The solids were determined according to the Standard Methods for the Examination of Water and Wastewater 23rd Edition - Method 2540 B, C and F. For total solids, an empty porcelain capsule is placed in a muffle furnace for 1 hour at $550-600^{\circ} \mathrm{C}$ and 1 more hour in the desiccator, then weighed in Analytical Balance $\left(P_{0}\right)$. The homogenized sample is introduced into the capsule that is kept in an oven for 3 days at 103-105 ${ }^{\circ} \mathrm{C}$, placed again in a desiccator for 1 hour and then weighed $\left(\mathrm{P}_{1}\right)$. Total solids are numerically calculated by the equation $T S=P_{1}-P_{0} / V$, where $V$ is the sample volume. The fractions of suspended solids were determined using a glass fiber membrane with $1.2 \mu$ pores as a filter and placed in a muffle furnace for 15 minutes at $550-600^{\circ}$ $C$ and another 1 hour in the desiccator, then weighed on a scale. Analytical $\left(P_{0}\right)$. The sewage samples are vacuum filtered and the filter containing the suspended residue is then taken to an oven for 1 hour at $103-105^{\circ} \mathrm{C}$, then stored in a desiccator for 1 hour and weighed on an analytical balance $\left(P_{1}\right)$. The value of suspended solids is calculated by the equation $S S=P_{1}-P_{0} / V$, where $V$ is the sample volume. Dissolved solids are calculated by difference, using the equation DS = TS - SS. For the determination of microbiological parameters, Total Coliforms and Escherichia coli, the Quanti-Tray / 2000 technique was used (IDEXX Laboratories Inc., Westbrook, ME, USA). This technique has $95 \%$ confidence and is performed according to the following steps: First the Colilert reagent is added in $100 \mathrm{~mL}$ of water sample and stirred. Then the sample is poured into a specific tray and sealed in a Quanti-Tray Sealer model $2 \mathrm{X}$. The tray is placed in an incubator at $35^{\circ} \mathrm{C}$ for 24 hours. After 24 hours the tray is removed and the yellow wells are counted, which is positive for total coliforms. For the detection of E. coli, the tray is transferred to a cabinet with UV light in a dark environment and counting the positive wells. The determination of the turbidity of the samples was made through direct reading in glass cuvettes of the Digimed DM-TU Turbidimeter equipment with calibration Traceable through Visomes.

\section{Results And Discussion}

\subsection{Morphological characterization of electrospun membranes. 3.1.1 Electrospinning: influence of process parameters in Diameter and arrangement of nanofibers}

From the experiment design, the 9 membranes with the smallest fiber diameter were selected according to the intended morphology to be used in the wastewater treatment process: PAN (293 $\pm 57 \mathrm{~nm}) ; \mathrm{PAN} / 0.5 \% \mathrm{AgNO}_{3}(277 \pm 63$ $\mathrm{nm}) ; \mathrm{PAN} / 1 \% \mathrm{AgNO}_{3}(251 \pm 58 \mathrm{~nm}) ; \mathrm{PAN} / 5 \% \mathrm{HPMC}(302 \pm 45 \mathrm{~nm}) ; \mathrm{PAN} / 5 \% \mathrm{HPMC} / 0.5 \% \mathrm{AgNO}_{3}(306 \pm 49 \mathrm{~nm})$; $\mathrm{PAN} / 5 \% \mathrm{HPMC} / 1 \% \mathrm{AgNO}_{3}(301 \pm 69 \mathrm{~nm}) ; \mathrm{PAN} / 10 \% \mathrm{HPMC}(297 \pm 54 \mathrm{~nm}) ; \mathrm{PAN} / 10 \% \mathrm{HPMC} / 0.5 \% \mathrm{AgNO}_{3}(286 \pm 51 \mathrm{~nm})$; $\mathrm{PAN} / 10 \% \mathrm{HPMC} / 1 \% \mathrm{AgNO}_{3}(281 \pm 65 \mathrm{~nm})$ Table SI1.

The influence of the parameters (flow rate, tip-collector distance, electric field) of the electrospinning process on the diameters and morphology of the resulting fibers was studied. In all the concentrations there was a slight increase in the average of the diameters of the fibers with the increase of the flow and a decreasing trend with the increase of 
the applied electric field. The average fiber diameter of PAN/10\% HPMC/1\% $\mathrm{AgNO}_{3}$ increased from $320 \pm 24$ to $402 \pm$ $43 \mathrm{~nm}$ with an increase in the flow rate and decreased from $376 \pm 70$ to $346 \pm 32 \mathrm{~nm}$ with an increase in the electric field. The same occurs with PAN/ $1 \% \mathrm{AgNO}_{3}$ fibers, which went from $289 \pm 19$ to $383 \pm 29 \mathrm{~nm}$ and from $341 \pm 48$ to $331 \pm 65 \mathrm{~nm}$, with an increase in flow rate and electric field, respectively. Similar results have been reported for the electrospinning of polycaprolactone [29] and polyimides [25]. In relation to the flow, the increase generally results in thicker fibers due to the greater mass in the formation of the fibers. The impact of the electric field is explained by the result of the greater stretching of the jet that produces finer fibers. For the parameter tip-collector distance, the average diameter of the fibers did not present a trend and varied with the increase of the tip-collector distance. In the electrospinning process, greater distances favor the electrospinning jet solvent to vaporize before the solidified fiber strand reaches the metallic collector, thus producing finer fibers. However, if this distance exceeds an ideal limit, the electric field may be reduced and the fiber will elongate less, resulting in a larger diameter.

Figure 2 SEM images of electrospun membranes: (A) PAN, (B) PAN $/ 0.5 \% \mathrm{AgNO}_{3}$, (C) PAN $/ 1 \% \mathrm{AgNO}_{3}$, (D) PAN/5\%HPMC, (E) PAN/5\%HPMC/0.5\%AgNO 3 , (F) PAN/5\%HPMC/1\%AgNO 3 , (G) PAN/10\%HPMC, (H) $\mathrm{PAN} / 10 \% \mathrm{HPMC} / 0.5 \% \mathrm{AgNO}_{3}$, (I) PAN/10\%HPMC/ $1 \% \mathrm{AgNO}_{3}$

Figure 2 shows the SEM micrographs of the selected membranes. One can see that the surface of the nanofibers is relatively smooth and few defects are found. The fibers of the membranes presented not significant variation concerning average diameter, that are between $251 \pm 58 \mathrm{~nm}$ and $306 \pm 49 \mathrm{~nm}$. Fig. SI 1 shows the SEM micrographs of the structures obtained by the electrospinning at various parameters of for a constant concentration (PAN/10\%HPMC/1\%AgNO 3 ). With a flow rate of $1 \mathrm{~mL} \cdot \mathrm{h}^{-1}$ and an electric field of $20 \mathrm{kV}$, the membranes showed defects in the formation of fibers, such as the appearance of beads. Reducing the electric field to $17 \mathrm{kV}$, the membranes stopped showing defects, however the average diameters were between $380 \pm 63$ and $464 \pm 57 \mathrm{~nm}$. Fibers without defects and with the smallest diameters (347 \pm 52 and $281 \pm 65 \mathrm{~nm}$ ), were obtained by reducing the flow rate to $0.5 \mathrm{~mL} \cdot \mathrm{h}^{-1}$. These results show an improvement in the spinning capacity of the fibers due to the change in the process parameters. In this case, the reduction in the flow rate and the electric field resulted in membranes without defects and a significant reduction in diameter. Through the experimental planning it was possible to optimize the electrospinning process, thus allowing the development and selection of membranes with intended morphology for application in wastewater treatment.

\subsubsection{Porosity}

The porosity of the membranes was measured to investigate the process optimization effect by modifying the electrospinning parameters determined in the experimental design. Figure 3 shows the variation in the porosity of electrospun membranes in relation to the diameters of their fibers and the results show high porosity and little variation, between $89.17 \pm 1.20$ and $91.60 \pm 1.22 \%$. The factor with the greatest influence on membrane porosity is the fiber diameters resulting from the electrospinning process [26]. In this case, as expected, the increase in porosity is consistent with the reduction in fiber diameter. Among the studied membranes, $\mathrm{PAN} / 1 \% \mathrm{AgNO}_{3}$ membrane, presented the highest porosity $(91.60 \pm 1.22 \%)$ and the smallest fiber diameter $(251 \pm 58 \mathrm{~nm})$, while the PAN/10\%HPMC membrane obtained the lowest porosity $(89.17 \pm 1.20 \%)$ and the largest fiber diameter (306 \pm 49 $\mathrm{nm}$ ). As observed in the morphological analysis of the membranes, the electrospinning parameters (flow, tip-collector distance, electric field) strongly influenced the diameters of the membrane fibers, which are responsible for the differences in porosity presented. The high porosity presented by membranes formulated with PAN, modified with $\mathrm{HPMC}$ and $\mathrm{AgNO}_{3}$ are an important property for wastewater treatment applications, together with the fiber diameter largely determine the penetration of water into the membrane and effectively control the retention rates of solids in 
the process filtration. High porosity, small pore size and large cumulative pore volumes provide several microporous channels that can significantly increase the flow of water and at the same time ensure the retention of fine particles, which is beneficial and favorable to increase performance and energy savings, fundamental properties in the wastewater treatment [30].

Figure 3 Diameter nanofibers versus porosity of electrospun membranes

\subsection{PAN-HPMC phase characterization in membranes by infrared spectroscopy (FTIR) and thermogravimetric analysis (TGA).}

The FTIR spectra of the nanostructured membranes of PAN and PAN/10\% HPMC/1\%AgNO 3 are shown in Fig. 4. The PAN membrane presents the characteristic signals at $2870-2930 \mathrm{~cm}^{-1}$ signals could be associated to the stretching ( $\mathrm{Y}$ ) of the group's $\mathrm{CH}$ and $\mathrm{CH}_{2}$ and to $2243 \mathrm{~cm}^{-1}$ to vibrations of the $\mathrm{\gamma C} \equiv \mathrm{N}$ groups.

Figure 4 Infrared spectra of PAN and PAN/10\%HPMC/1\%AgNO 3 nanostructured membranes

The signal at $1454 \mathrm{~cm}^{-1}$ is attributed to methylene $\left(\mathrm{CH}_{2}\right)$ bending and at $1253 \mathrm{~cm}^{-1}$ could be identify the $\mathrm{C}-\mathrm{N}$ stretching $[17,31]$.

The spectrum of the PAN/10\% $\mathrm{HPMC} / 1 \% \mathrm{AgNO}_{3}$ membrane (Fig. 4), show a characteristic absorption at $3468 \mathrm{~cm}^{-1}$ due to $-\mathrm{OH}$ of HPMC and at $2926 \mathrm{~cm}^{-1}$ overlaps absorptions of $\mathrm{YCH}_{2}$ and $\mathrm{\delta CH}_{2}$ characteristic of the both phases (PAN and HPMC) present in the nanofibers.

The existence of dipole-dipole interactions between the $-\mathrm{OH}$ and $\mathrm{C} \equiv \mathrm{N}$ polymer groups in the PAN and $\mathrm{PAN} / 10 \% \mathrm{HPMC} / 1 \% \mathrm{AgNO}_{3}$ membranes affected the intensity ratio of the $\mathrm{C} \equiv \mathrm{N}_{2243} / \mathrm{CH}_{2293}$ signals. The intensity ratio in the PAN, 0.82 , change to 1.11 when the intensity ratio in the PAN, 0.82 , went to 1.1 after the membranes were added with $10 \% \mathrm{HPMC}$ and $1 \% \mathrm{AgNO}_{3}$. Additionally, 1078 signal due to the $\mathrm{CO}$ present in the HPMC structure shows a slight displacement up to $1070 \mathrm{~cm}^{-1}$ and the $\mathrm{CO}_{1070} / \mathrm{CH}_{1454}$ intensity ratio varies from 1.05 in the PAN to 1.17 in the PAN/10\% $\mathrm{HPMC} / 1 \% \mathrm{AgNO}_{3}$ membrane. The FTIR analysis of the PAN $/ 1 \% \mathrm{AgNO}_{3}$ membrane, no changes in the spectrum were observed with the presence of silver in the PAN nanofibers [32,33]. This suggests an intramolecular homogeneity of the electrospun membranes, where the properties of the fibers are enhanced after being modified with $\mathrm{HPMC}$ and added with $\mathrm{AgNO}_{3}$.

Figure 5 TGA/DTG analysis of PAN, PAN/1\%AgNO 3 , PAN/10\%HPMC and PAN/10\%HPMC/ $\% \mathrm{AgNO}_{3}$ nanostructured membranes

The thermogravimetric behavior of PAN membrane formulations could be observed in (Fig. 5). The PAN/10\%HPMC membrane from these polymer blend presented a degradation onset temperature $\left(\mathrm{T}_{\text {onset }}\right)$ at $282^{\circ} \mathrm{C}$ and maximum degradation rate temperature $\left(\mathrm{T}_{\max }\right)$ in $284,6^{\circ} \mathrm{C}$. These degradation temperatures were lower than PAN membrane ( $\mathrm{T}_{\text {onset }} 291^{\circ} \mathrm{C}, \mathrm{T}_{\max } 297^{\circ} \mathrm{C}$ ), behavior that could be associated to interaction between HPMC and PAN polymer phases. The membranes $\mathrm{PAN} / 1 \% \mathrm{AgNO}_{3}$ and $\mathrm{PAN} / 10 \% \mathrm{HPMC} / 1 \% \mathrm{AgNO}_{3}$ show similar thermal behavior in presence of $1 \% \mathrm{AgNO}_{3}$. Their second thermal degradation in both membranes show a weight loss at $378^{\circ} \mathrm{C} t$ lower temperatures of PAN and PAN/10\%HPMC, which was consequence to $\mathrm{AgNO}_{3}$ presence $[34,35]$. The thermogravimetric behavior and Infrared spectroscopies characterization support the compatibility of 


\subsection{Wettability of PAN membranes modified with HPMC and $\mathrm{AgNO}_{3}$}

The adding HPMC to PAN was to increase hydrophilicity (wettability) in order to enhance permeability and decrease the tendency of fouling on the membrane during the filtration process. The wettability results of the membranes were appreciated from the contact angle measured in samples (A) PAN, (B) PAN/0.5\% $\mathrm{AgNO}_{3}$ and (C) PAN $/ 1 \% \mathrm{AgNO}_{3}$, which showed a reduction in the contact angle due to the insertion and increased concentration of $\mathrm{AgNO}_{3}(\mathrm{Fig} .6)$. In samples PAN/5\%HPMC; PAN/5\%HPMC/0.5\%AgNO 3 ; PAN/5\%HPMC/1\%AgNO 3 ; PAN/10\%HPMC; $\mathrm{PAN} / 10 \% \mathrm{HPMC} / 0.5 \% \mathrm{AgNO}_{3} ; \mathrm{PAN} / 10 \% \mathrm{HPMC} / 1 \% \mathrm{AgNO}_{3}$, the spreading speed of the applied water drop did not allow the measurement of the contact angle, and this is characteristic of superhydrophilic surface.

Figure 6 Images of contact angle concerning nanostructured membranes: (A) PAN, (B) PAN/0.5\%AgNO 3 , (C) $\mathrm{PAN} / 1 \% \mathrm{AgNO}_{3}$

By adding $0.5 \%$ of $\mathrm{AgNO}_{3}$, it was possible to decrease the membrane contact angle from $116.18^{\circ}(\mathrm{A})$ to $93.01^{\circ}(\mathrm{B})$, and after the addition of $1.0 \%$ of $\mathrm{AgNO}_{3}(\mathrm{C})$, there was an even more intense reduction of the contact angle to $37.01^{\circ}$. This fact may be related to the difference in porosity between membranes (A) $90.52 \pm 1.25 \%$; (B) $91.53 \pm 1.26 \%$ and (C) $91.60 \pm 1.22 \%$, which can alter the surface contact between the fiber and the applied water drop. When comparing the diameter of the membrane fibers (A) $293 \pm 57 \mathrm{~nm}$; (B) $277 \pm 63 \mathrm{~nm}$ and (C) $251 \pm 58 \mathrm{~nm}$, a reduction in the diameter of the fibers can be observed, which may have led to an increase in the contact surface and porosity. This fact can be observed in the studies by [36], in which the addition of silver particles to electrophilic membranes caused an increase in hydrophilicity in the membranes, as it reduced the thickness of the fibers that make up the membrane and consequently increased its porosity.

In membrane samples PAN/5\%HPMC; PAN/5\%HPMC/0.5\%AgNO 3 ; PAN/5\%HPMC/1\%AgNO $;$ PAN/10\%HPMC; $\mathrm{PAN} / 10 \% \mathrm{HPMC} / 0.5 \% \mathrm{AgNO}_{3} ; \mathrm{PAN} / 10 \% \mathrm{HPMC} / 1 \% \mathrm{AgNO}_{3}$, the incorporation of $\mathrm{HPMC}$ was expected to make the membranes hydrophilic. However, this effect proved to be very intense and the measurements of the contact angle for all samples containing HPMC were not possible, because the propagation of the drop of water on the membrane surface was instantaneous, not providing enough time to measure the contact angle. The addition of HPMC, due to its hydrophilic nature, caused a significant reduction in the contact angle that started to tend to 0 (zero), characterizing the superhydrophilic membrane. The increase in hydrophilicity in the membranes is one of the objectives of this study, because through this property, membranes with high permeability and low incidence of encrustations can be obtained, which are fundamental characteristics for membranes used in filtration to wastewater treatment.

\subsection{Permeability}

In a hydrophilic membrane, water molecules can be spontaneously absorbed on the membrane surface in the separation process, which favors increased flow and water permeability. The performance of the membranes in terms of permeability was obtained at 3 different pressures $(0.3,0.4$ and 0.5 bar) and are shown in Fig. 7.

PAN membranes modified with $\mathrm{HPMC}$ and $\mathrm{AgNO}_{3}$, showed greater permeate flow compared to the original PAN membrane. When compared to the highest pressure used ( 0.5 bar), the permeate flow of the membrane modified 
with $\mathrm{AgNO}_{3}$, has a $51 \%$ increase in PAN $\left(7.713 \pm 433 \mathrm{~L} \cdot \mathrm{m}^{-2} \cdot \mathrm{h}^{-1}\right)$ for PAN/ $1 \% \mathrm{AgNO}_{3}\left(11.657 \pm 310 \mathrm{~L} \cdot \mathrm{m}^{-2} \cdot \mathrm{h}^{-1}\right)$. In PAN/5\%HPMC (15.434 $\left.\pm 275 \mathrm{~L} . \mathrm{m}^{-2} \cdot \mathrm{h}^{-1}\right)$ and PAN/10\%HPMC (18.471 $\left.\pm 225 \mathrm{~L} \cdot \mathrm{m}^{-2} \cdot \mathrm{h}^{-1}\right)$ membranes, there is an increase of 100 and $139 \%$ respectively in relation to PAN. When comparing PAN and PAN $10 \% \mathrm{HPMC} / 1 \% \mathrm{AgNO}_{3}$ membranes, the results show a significant increase of $174 \%$ in water flow, from $7.713 \pm 433 \mathrm{~L}^{\mathrm{m}} \mathrm{m}^{-2} \cdot \mathrm{h}^{-1}$ to $21.151 \pm$ 445 L. $\mathrm{m}^{-2} \cdot \mathrm{h}^{-1}$.

As all membranes have the same thickness and porosity range, the membrane permeability results show that the effect of hydrophilicity as a function of the concentrations of $\mathrm{HPMC}$ and $\mathrm{AgNO}_{3}$, results in a significant increase in the performance of the membranes in relation to the permeate flow.

Figure 7 Permeability of nanostructured filtering membranes

When comparing the permeability results of this research with recent studies that also analyzed the permeability of modified PAN membranes, the results for permeate flow presented by [37] with PAN membranes incorporated with polycitrate-para-aminobenzoate nanoparticles $3 \%$ alumoxane (PC-PABA) reached $3,321 \mathrm{~L}^{-\mathrm{m}^{-2}} \mathrm{~h}^{-1}$. [38] observed an even greater water flow, about 4,000 L.m $\mathrm{m}^{-2} \cdot \mathrm{h}^{-1}$ in the PAN_130_50_3 membrane, which after being electrospun, were

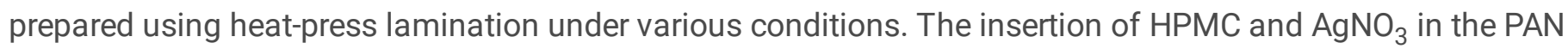
membranes studied, effectively contributed to the chemical modification on the membrane surface. And hydrophilicity resulting from these changes, provides a significant impact on the performance of the water flow.

\subsection{Wastewater treatment \\ 3.5.1. Wastewater sample}

The sample of mine wastewater collected (A-Gross) in the CBA / Votorantim tailings dam analyzed (Table 3) was characterized by suspended solids $(4,693.50 \mathrm{mg} / \mathrm{mL})$ and turbidity $(19,000 \mathrm{NTU})$. These high rates did not allow the analysis of total coliforms and Escherichia coli, which were carried out after the primary and secondary stages of treatments.

\subsubsection{Primary wastewater step treatment}

The primary wastewater step treatment with quaternized chitosan [28] reduce the turbidity index from 19,000 NTU to 14.73 NTU (Table 2), with an efficiency rate of $99.92 \%$. After being modified through quaternization, chitosan starts to have a greater cationic character and due to its broader branched molecular architecture, it is possible to aggregate a greater number of colloidal particles. This has increased its efficiency in reducing turbidity, making this water suitable for filtering.

Table 2 Raw water analysis, after primary treatment

\subsubsection{Second wastewater step treatment.}

After filtering the A-Primary water, the membranes were dried, and prepared for SEM analyses. The micrograph (Fig. 8) shows suspended and colloidal particles adheres to the fibers and a layer is formed on the membrane surface. In membranes PAN/0.5\%AgNO 3 , PAN/5\%HPMC/0.5\%AgNO $3, \mathrm{PAN} / 5 \% \mathrm{HPMC} / 1 \% / \mathrm{AgNO}_{3}$, and $\mathrm{PAN} / 10 \% \mathrm{HPMC} / 0.5 \% \mathrm{AgNO}_{3}$ it is possible to observe empty spaces between the pores that were not completely filled by the retained solids, as well as polymeric fibers belonging to the membranes that were not covered.

Figure 8 SEM images of nanostructured membranes after bauxite effluent filtration

Page $11 / 23$ 
As shown in Fig. 8, the membranes after the wastewater treatment clearly shows a large amount of suspended particulate material that adheres to the surface of the membranes. The filtration of wastewater depends a lot on the quantity and size of the particles of contaminants present in the water, which can contribute to the increase of fouling and reduce the life of the membrane. In this study, two factors contributed significantly to guarantee the performance of the wastewater treatment achieved by the membranes. The primary treatment, that significantly reduced the suspended solid particulate material of wastewater and the high hydrophilicity presented by the modified membranes that gave the membranes antifouling properties.

Table 3 presents the results of the analysis of wastewater A-Primary before and after going through the second treatment step with PAN and PAN/HPMC/ $\mathrm{AgNO}_{3}$ membranes. To evaluate the results, the drinking water standards established by the WHO were considered. In general, the formulated membranes reduced virtually all tested parameters.

The microbiological parameters, Total Coliforms and Escherichia coli, which are used as indicators of treatment efficiency and fecal contamination, respectively, showed an absent result in all evaluated membranes. This result is in agreement with the researched literature [39], who report the high efficiency in bacterial removal presented by membranes in filtration processes.

Table 3 Analysis of water after filtration using different formulations of PAN nanostructured membranes Concerning aluminum, all results were below the established limit, with a maximum reduction of 0.324 to 0.0081 $\mathrm{mg} / \mathrm{L}$. Water conductivity was stable for all samples. In regard to iron, there was a non-uniform reduction similar to the other tested parameters. However, four results were above the maximum established limit. Although manganese is already below the limit after the primary treatment only, filtration efficiency of virtually all membranes was $50 \%$.

Concerning the retention of suspended solids from the wastewater, all electrospun membranes obtained significant results, with a maximum reduction from $658.43 \mathrm{mg} / \mathrm{L}$ to $21.79 \mathrm{mg} / \mathrm{L}$ and removal efficiency of $95.78 \%$. The retention of suspended solids is greatly due to the morphology of the membrane pores, which in this case are formed by a tangle of very thin overlapping fibers, granting the membrane a high contact surface, which favors the retention of most solid material present in the wastewater. This fact can be seen in the images of the membranes (Fig. 9) in which all membranes, after being used in filtration, had a large number of solids retained on the surface.

Figure 9 Before and after images concerning nanostructured filtering membranes use for bauxite wastewater treatment

The relationship between these parameters, turbidity and suspended solids, can be seen in the results presented after the mining wastewater. When the results obtained are analyzed (Fig. 10) and the efficiency in filtration for the evaluated membranes is achieved, a trend in reducing these parameters can be seen.

Figure 10 Relationship between turbidity and suspended solids after filtration

The presence of particles of varying sizes suspended in water, such as clay, silt, finely divided organic matter, plankton and other microscopic organisms can make water look cloudy or muddy. These factors are considered to be the main causes of water turbidity. In the case of bauxite tailings, the main cause of high turbidity in are the clay particles present in the ore, which, when broken down in the beneficiation process, remain suspended in the water. 
This integrated system, primary (quaternized chitosan) and secondary processes with $\mathrm{PAN} / 10 \% \mathrm{HPMC} / 1 \% \mathrm{AgNO}_{3}$ nano-fiber hydrophilic membrane is effective in the process of filtering and framing water in the who drinking parameters.

\section{Conclusions}

Different PAN/HPMC/AgNO 3 composition were formulated and establish electrospinning parameters to obtain a nanostructured membrane which were characterize. The PAN/10\%HPMC/1\%AgNO 3 membrane show higher hydrophilicity and high porosity. The morphologies were characterized by uniform fiber with average diameter between: $251 \pm 58$ and $306 \pm 49 \mathrm{~nm}$. These characteristics improved the permeability behavior $\left(21,151 \pm 445 \mathrm{~L} \cdot \mathrm{m}^{-2} \cdot \mathrm{h}^{-}\right.$

$\left.{ }^{1}\right)$ and the performance to wastewater dam turbidity reduction which after filtration rich 0.58 NTU index with an efficiency of $96.06 \%$. After this second process step, joint to reduction turbidity the pathogenic microorganisms, Total Coliforms and Escherichia coli were eliminated, obtaining a water with the characteristic parameters of drinking water.

The efficiency of this membrane, eliminating turbidity and pathogenic microorganisms, added to the high flow rate cross the membranes classified it to potential use in integrated wastewater treatment processes and adequate waste water management which could be avoid the accumulation of large volumes of water in the dam and consequently their impact on stability reducing the risks of environmental disasters.

\section{Declarations}

\section{Acknowledgements}

The authors gratefully acknowledge the CBA/Votorantim, Membrane Separation Processes Laboratory COPPE/UFRJ, Electron Microscopy Platform Rudolf Barth - FIOCRUZ for technical collaboration, FAPERJ (E-26/ 201.592/2014) and CNPq (310108/2017-9) for financial support.

\section{Compliance with Ethical Standards}

Conflict of interest: The authors declares that they have no conflict of interest.

\section{References}

1. Armstrong M, Petterd, R, Petterd C (2019) Why have so many tailings dams failed in recent years? Resources Policy 63, 101-112.

2. Valeriano CM, Neumann R, Alkmim AR, Evangelista H, Heilbron M, Neto CCA, Souza GP (2019) Sm-Nd and Sr isotope fingerprinting of iron mining tailing deposits spilled from the failed SAMARCO Fundão dam 2015 accident at Mariana, SE-Brazil Applied Geochemistry. 106, 34-44.

3. Dong L, Deng S, Wang F (2020) Some developments and new insights for environmental sustainability and disaster control of tailings dam, Journal of Cleaner Production. https://doi.org/10.1016/j.jclepro.2020.122270.

4. Rotta LHS, Alcântara E, Park E, Negri RG, Lin YN, Bernardo N, Mendes TSG, Filho CRS (2020) The 2019 Brumadinho tailings dam collapse: Possible cause and impacts of the worst human and environmental disaster in Brazil. Int J Appl Earth Obs Geoinformation. 90, 102119.

5. Kunz NC (2016) Catchment-based water management in the mining industry: Challenges and solutions. The Extractive Industries and Society. DOI: 10.1016/j.exis.2016.10.012. 
6. Ives KJ (1970) Review paper rapid filtration. Water Research Pergamon Press. 4, 201-223.

7. Bauer MJ, Bayley R, Chipps MJ, Eades A, Scriven RJ, Rachwal AJ (1998) Enhanced rapid gravity filtration and dissolved air flotation for pre-treatment of river thames reservoir water. War. Sci. Tech. 31 (2), 35-42.

8. Marais SS, Ncube EJ, Msagati TAM, Mamba BB, Nkambule TTI (2018) Comparison of Natural Organic Matter Removal by Ultrafiltration, Granular Activated Carbon Filtration and Full-Scale Conventional Water Treatment, Journal of Environmental Chemical Engineering. https://doi.org/10.1016/j.jece.2018.10.002.

9. Hoslett J, Massara TM, Malamis S, Ahmad D, Boogaert IVD, Katsou E, Ahmad B, Ghazal H, Simons S, Wrobel L, Jouhara H (2018) Surface water filtration using granular media and membranes: A review. Science of the Total Environment. 639,1268-1282

10. Grylewicz A, Mozia S (2020) Polymeric mixed-matrix membranes modified with halloysite nanotubes for water and wastewater treatment: a review, Separation and Purification Technology. (2020) doi: https://doi.org/10.1016/j.seppur.2020.117827.

11. Li C, Ma H, Venkateswaran S, Hsiao BS (2020) Sustainable carboxylated cellulose filters for efficient removal and recovery of lanthanum, Environmental Research, https://doi.org/10.1016/j.envres.2020.109685.

12. Kong X, Jinxing Ma J, Le-Clech P, Wang Z, Tang CY, Waite TD (2020) Management of concentrate and waste streams for membrane-based algal separation in water treatment: A review. Water Research. 183, 115969.

13. Nataraj SK, Yangb KS, Aminabhavi TM (2012) Polyacrylonitrile-based nanofibers-A state-of-the-art review. Progress in Polymer Science. 37, 487- 513.

14. Cui J, Li F, Wang Y, Zhang Q, Ma W, Huanga C (2020) Electrospun nanofiber membranes for wastewater treatment applications. Separation and Purification Technology. https://doi.org/10.1016/j.seppur.2020.117116.

15. Chen H, Huang M, Liu Y, Meng L, Ma M (2020) Functionalized electrospun nanofiber membranes for water treatment: A review. Science of the Total Environment 739, 139944.

16. Kumar TSM, Senthilkumar K, Ratanit M, Rajini N, Chanunpanich N, Hariram N, Pornwongthong P, Siengchin S (2019) Influence of Titanium Dioxide Particles on the Filtration of 1,4-Dioxane and Antibacterial Properties of Electrospun Cellulose Acetate and Polyvinylidene Fluoride Nanofibrous Membranes. Journal of Polymers and the Environment. https://doi.org/10.1007/s10924-020-01919-0.

17. Wang X, Pan S, Zhang M, Qi J, Sun X, Gu C, Wang L, Li,J (2019) Modified hydrous zirconium oxide/PAN nanofibers for efficient defluoridation from groundwater. Science of the Total Environment. 685, 401-409.

18. Pereao O, Bode-Aluko C, Laatikainen K, Nechaev A, Petrik L (2020) Morphology, Modification and Characterisation of Electrospun Polymer Nanofiber Adsorbent Material Used in Metal Ion Removal. Journal of Polymers and the Environment (2019) 27:1843-1860. https://doi.org/10.1007/s10924-019-01497-w.

19. Jankowska K, Zdarta J, Grzywaczyk A, Kijeńska-Gawrońska E, Biadasz A, Jesionowski T (2020) Electrospun poly(methyl methacrylate)/polyaniline fibres as a support for laccase immobilisation and use in dye decolourisation. Environmental Research. 184, 109332.

20. Fane AG, Tang CY, Wang R (2006) Membrane Technology for Water: Microfiltration, Ultrafiltration, Nanofiltration, and Reverse Osmosis. Elsevier B.V.

21. Zhu Y, Chen D (2017) Preparation and characterization of attapulgite-based nanofibrous membranes. Materials and Design. 113, 60-67.

22. Paul M, Jons SD (2016) Chemistry and fabrication of polymeric nanofiltration membranes: A review, Polymer (2016), doi: 10.1016/j.polymer.2016.07.085. 
23. Alharbi AR, Alarifi IM, Khan WS. Asmatulu R (2016) Highly Hydrophilic Electrospun Polyacrylonitrile/ Polyvinypyrrolidone Nanofibers Incorporated with Gentamicin as Filter Medium for Dam Water and Wastewater Treatment. Journal of Membrane and Separation Technology. 5, 38-56.

24. Almuhamed S, Bonne M, Khenoussi N, Brendle J, Schacher L, Lebeau B, Adolphe DC (2015) Electrospinning composite nanofibers of polyacrylonitrile/synthetic Na-montmorillonite. Journal of Industrial and Engineering Chemistry. Volume 35, 25, 146-152. https://doi.org/10.1016/j.jiec.2015.12.024.

25. Topuz F, Abdulhamid MA, Holtzl T, Szekely G (2021) Nanofiber engineering of microporous polyimides through electrospinning: Influence of electrospinning parameters and salt addition. Materials and Design. 198, 109280.

26. Ma X, Kolla P, Yang R, Wang Z, Zhao Y, Smirnova AL, Fonga H (2017) Electrospun polyacrylonitrile nanofibrous membranes with varied fiber diameters and different membrane porosities as lithium-ion battery separators. Electrochimica Acta 236, 417-423.

27. Sundaran PS, Reshmi CR, Sagitha P, Manaf O, Sujith A (2019) Multifunctional graphene oxide loaded nanofibrous membrane for removal of dyes and coliform from water. Journal of Environmental Management. 240, 494-503.

28. Bigogno RG, Sanchez RJR, Abreu MF (2018) Quaternized Chitosan for Ecological Treatment of Bauxite Mining Effluents. Journal of Polymers and the Environment.26,4169-4175.

29. Beachley V, Wen X (2009) Effect of electrospinning parameters on the nanofiber diameter and length, materials science \& engineering, C, Materials for biological applications. 3, 663-668.

30. Wang N, Si Y, Wang N, Sun G, El-Newehy M, Al-Deyab SS, Ding B (2014) Multilevel structured polyacrylonitrile/silica nanofibrous membranes for high-performance air filtration. Separation and Purification Technology. 126, 44-51.

31. Karbownik I, Rac-Rumijowska O, Fiedot-Toboła M, Rybicki T, Teterycz H (2019) The Preparation and Characterization of Polyacrylonitrile-Polyaniline (PAN/PANI) Fibers. Materials. 12, 664, 2019; doi:10.3390/ma12040664.

32. Bortolassi ACC, Nagarajan S, Lima BA, Guerra VG, Aguiar ML, Huon V, Soussan L, Cornu D, Miele P, Bechelany M (2019) Efficient nanoparticles removal and bactericidal action of electrospun nanofibers membranes for air filtration. Materials Science \& Engineering C 102, 718-729.

33. Rehan M, Nada AA, Khattab TA, Abdelwahed NAM, El-Kheir AAA (2020) Development of multifunctional polyacrylonitrile/silver nanocomposite films:Antimicrobial activity, catalytic activity, electrical conductivity, UV protection and SERS-active sensor. https://doi.org/10.1016/j.jmrt.2020.05.079.

34. Shen X, Yu D, Zhang X, White CB, Zhu L (2011) Preparation and Characterization of TAM-Loaded HPMC/PAN Composite Fibers for Improving Drug-Release Profiles, Journal of Biomaterials Science, Polymer Edition, 22:16, 2227-2240, DOI: 10.1163/092050610X538182.

35. Ke H, Wei Q (2019) Determining influences of silver nanoparticles on morphology and thermal properties of electrospun polyacrylonitrile-based form-stable phase change composite fibrous membranes loading fatty acid ester/eutectics. Thermochimica Acta. 671, 10-16.

36. Behboudi A, Jafarzadeh Y, Yegani R (2018) Incorporation of silica grafted silver nanoparticles into polyvinyl chloride/polycarbonate hollow fiber membranes for pharmaceutical wastewater treatment. Chemical Engineering Research and Design https://doi.org/10.1016/j.cherd.2018.03.019.

37. Moradi G, Zinadini S (2018) Polycitrate-para-aminobenzoate alumoxane nanoparticles as a novel nanofiller for enhancement performance of electrospun PAN membranes. Separation and Purification Technology. doi: https: //doi.org/10.1016/j. seppur.2018.12.037. 
38. Roche R, Yalcinkaya F (2019) Electrospun Polyacrylonitrile Nanofibrous Membranes for Point-of-Use Water and Air Cleaning. ChemistryOpen. 8, 97-103. DOI: 10.1002/open.201800267.

39. Sundaran PS, Reshmi CR, Sagitha P, Sujith A (2017) Electrospun Nanofibrous Membranes for Water Purification, Polymer Reviews, 57:3, 467-504, DOI: 10.1080/15583724.2017.1309664.

\section{Tables}

Table 1 Experimental design for the electrospinning of the polyacrylonitrile nanofibers

\begin{tabular}{|ll|}
\hline Parameter & Parameter level \\
\hline HPMC concentration (\%wt) & $0,5,10$ \\
\hline $\mathrm{AgNO}_{3}$ Concentration (\%wt) & $0,0.5,1$ \\
\hline Flow rate $\left(\mathrm{mL} \cdot \mathrm{h}^{-1}\right)$ & $0.5,1$ \\
\hline Tip-to-collector distance (TCD, cm) & $10,15,20$ \\
\hline Electrical field $(\mathrm{kV})$ & 17,20 \\
\hline
\end{tabular}

Table 2 Raw water analysis, after primary treatment

\begin{tabular}{|llll|}
\hline Parameter & Unity & A-Gross & A-Primary \\
\hline Aluminum & $\mathrm{mg} / \mathrm{L}$ & 0.666 & 0.556 \\
\hline Total Coliforms & $\mathrm{NMP} / 100 \mathrm{~mL}$ & $\mathrm{x}$ & 5.2 \\
\hline Escherichia coli & $\mathrm{NMP} / 100 \mathrm{~mL}$ & $\mathrm{x}$ & $<1.00$ \\
\hline Iron & $\mathrm{mg} / \mathrm{L}$ & 597.5 & 0.696 \\
Manganese & $\mathrm{mg} / \mathrm{L}$ & 4 & 0.01 \\
\hline pH & $\mathrm{U} \mathrm{pH}$ & 5.5 & 8.4 \\
\hline Suspended Solids & $\mathrm{mg} / \mathrm{L}$ & $4,693.50$ & 658.43 \\
\hline Turbidity & $\mathrm{NTU}$ & 19,000 & 14.73 \\
\hline NA = not applicable & & & \\
\hline
\end{tabular}

Table 3 Analysis of water after filtration using different formulations of PAN nanostructured membranes 


\begin{tabular}{|c|c|c|c|c|c|c|c|c|}
\hline & Aluminum & $\begin{array}{l}\text { Total } \\
\text { Coliforms }\end{array}$ & $\begin{array}{l}\text { Escherichia } \\
\text { coli }\end{array}$ & Iron & Manganese & $\mathrm{pH}$ & $\begin{array}{l}\text { Suspended } \\
\text { Solids }\end{array}$ & Turbidity \\
\hline & $(\mathrm{mg} / \mathrm{L})$ & $\begin{array}{l}(\mathrm{NMP} / 100 \\
\mathrm{mL})\end{array}$ & $\begin{array}{l}\text { (NMP/100 } \\
\mathrm{mL})\end{array}$ & $(\mathrm{mg} / \mathrm{L})$ & $(\mathrm{mg} / \mathrm{L})$ & & $(\mathrm{mg} / \mathrm{L})$ & (NTU) \\
\hline Uncertainty & \pm 0.02 & - & - & \pm 0.02 & \pm 0.02 & $\stackrel{ \pm}{0.3}$ & \pm 3.4 & \pm 0.01 \\
\hline $\begin{array}{l}\text { Before } \\
\text { filtration }\end{array}$ & 0.556 & 5.2 & $<1.00$ & 0.696 & 0.055 & 6.6 & 658.43 & 14.73 \\
\hline $\begin{array}{l}\text { PAN / 0\% } \\
\text { HPMC / } \\
0 \% \mathrm{Ag}\end{array}$ & 0.126 & Absent & Absent & 0.297 & 0.013 & 6.9 & 41.39 & 1.61 \\
\hline $\begin{array}{l}\text { PAN / 0\% } \\
\text { HPMC / } \\
0,5 \% \text { Ag }\end{array}$ & 0.075 & Absent & Absent & 0.173 & 0.015 & 7.7 & 29.23 & 0.61 \\
\hline $\begin{array}{l}\text { PAN / 0\% } \\
\text { HPMC / } \\
1 \% \mathrm{Ag}\end{array}$ & 0.093 & Absent & Absent & 0.424 & 0.021 & 6.5 & 34.9 & 1.03 \\
\hline $\begin{array}{l}\text { PAN / 5\% } \\
\text { HPMC / } \\
0 \% \mathrm{Ag}\end{array}$ & 0.092 & Absent & Absent & 0.189 & 0.015 & 7 & 26.02 & 0.7 \\
\hline $\begin{array}{l}\text { PAN / 5\% } \\
\text { HPMC / } \\
0,5 \% \text { Ag }\end{array}$ & 0.09 & Absent & Absent & 0.219 & 0.021 & 6.6 & 21.79 & 0.65 \\
\hline $\begin{array}{l}\text { PAN / 5\% } \\
\text { HPMC / } \\
1 \% \mathrm{Ag}\end{array}$ & 0.157 & Absent & Absent & 0.326 & 0.025 & 7.2 & 27.52 & 0.64 \\
\hline $\begin{array}{l}\text { PAN / 10\% } \\
\text { HPMC / } \\
0 \% \text { Ag }\end{array}$ & 0.121 & Absent & Absent & 0.204 & 0.015 & 6.9 & 32.07 & 0.93 \\
\hline $\begin{array}{l}\text { PAN / 10\% } \\
\text { HPMC / } \\
0,5 \% \text { Ag }\end{array}$ & 0.081 & Absent & Absent & 0.444 & 0.045 & 7 & 22.43 & 0.58 \\
\hline $\begin{array}{l}\text { PAN / 10\% } \\
\text { HPMC / } \\
1 \% \text { Ag }\end{array}$ & 0.102 & Absent & Absent & 0.336 & 0.026 & 7.3 & 36.68 & 0.91 \\
\hline$N A=$ not ap & able & & & & & & & \\
\hline
\end{tabular}

\section{Figures}



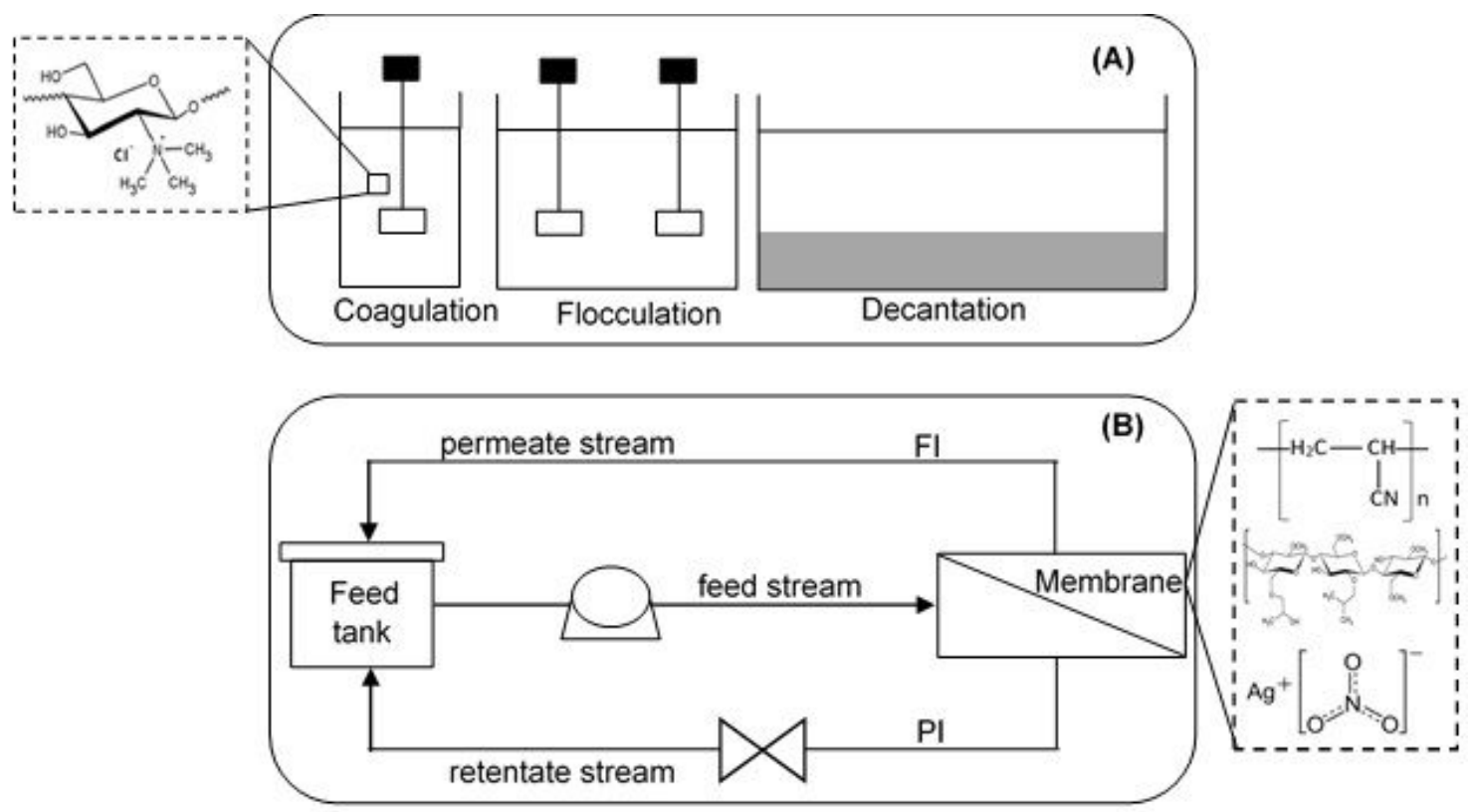

\section{Figure 1}

Schematic representation of the experimental configuration of the integrated wastewater treatment system. (A) Primary treatment; (B) Membrane filtration, PI and FI are pressure and flowrate indicators, respectively

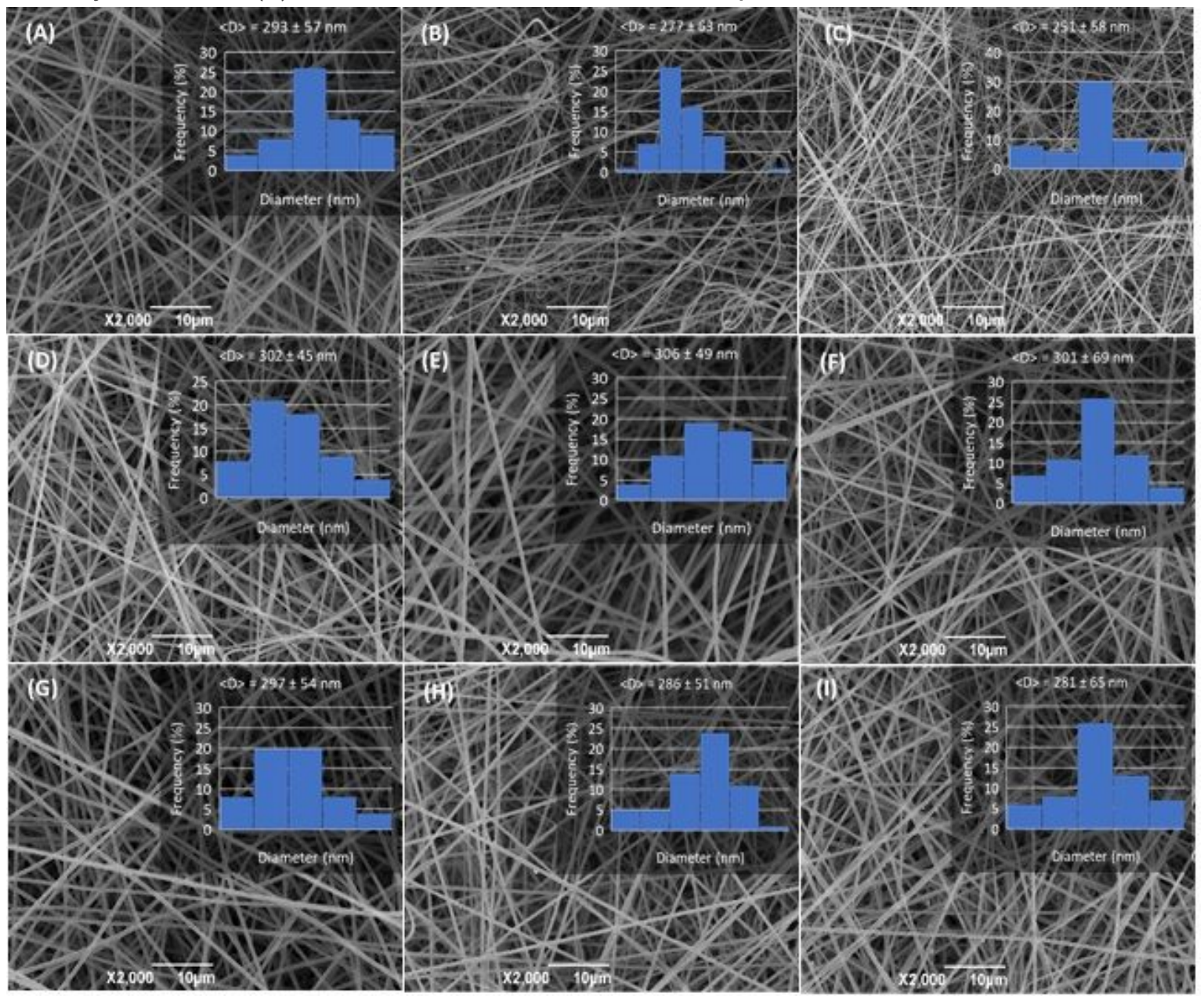

\section{Figure 2}


SEM images of electrospun membranes: (A) PAN, (B) PAN/0.5\%AgNO3, (C) PAN/1\%AgNO3, (D) PAN/5\%HPMC, (E) PAN/5\%HPMC/0.5\%AgNO3, (F) PAN/5\%HPMC/1\%AgNO3, (G) PAN/10\%HPMC, (H) PAN/10\%HPMC/0.5\%AgNO3, (I) $\mathrm{PAN} / 10 \% \mathrm{HPMC} / 1 \% \mathrm{AgNO} 3$

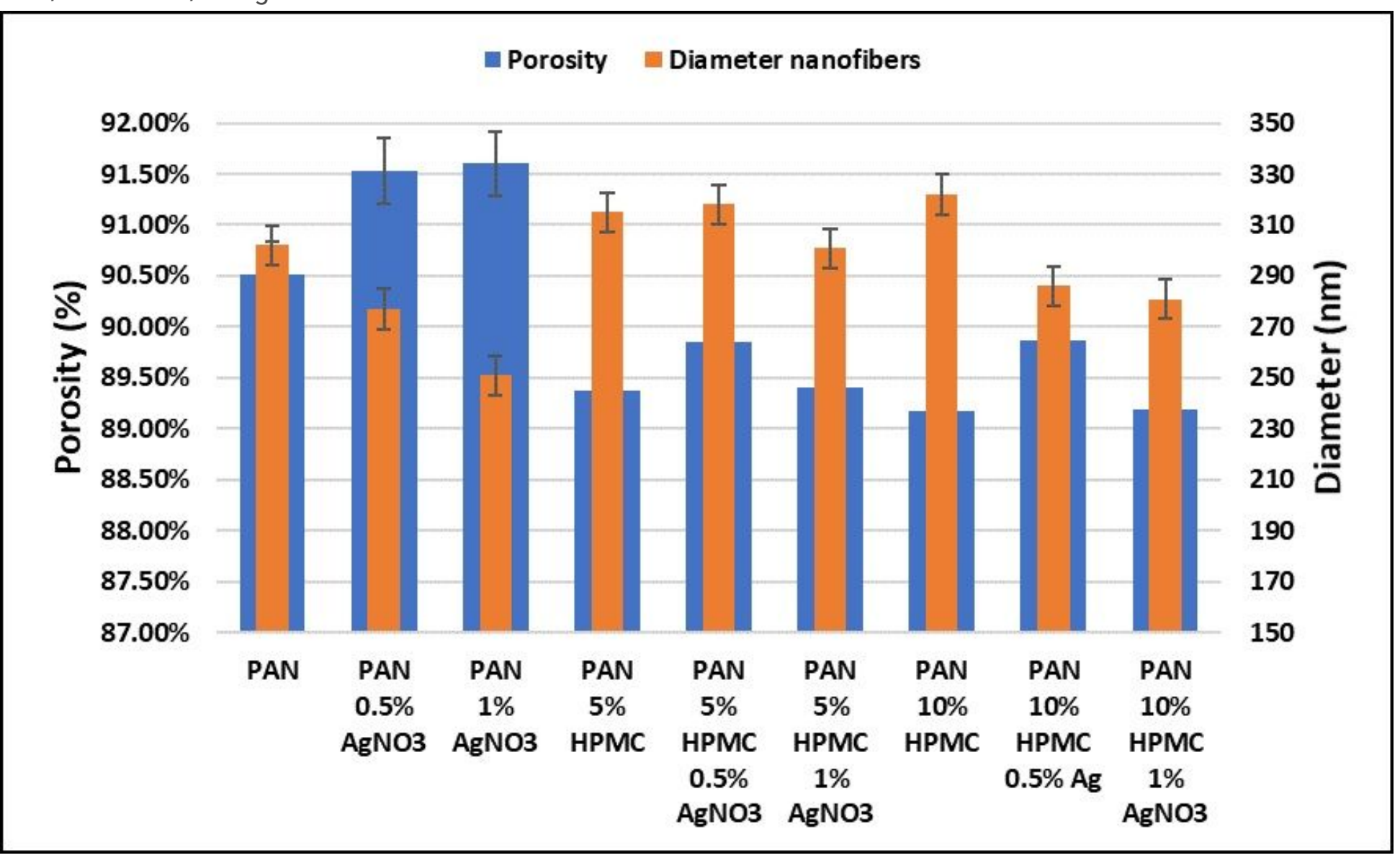

Figure 3

Diameter nanofibers versus porosity of electrospun membranes

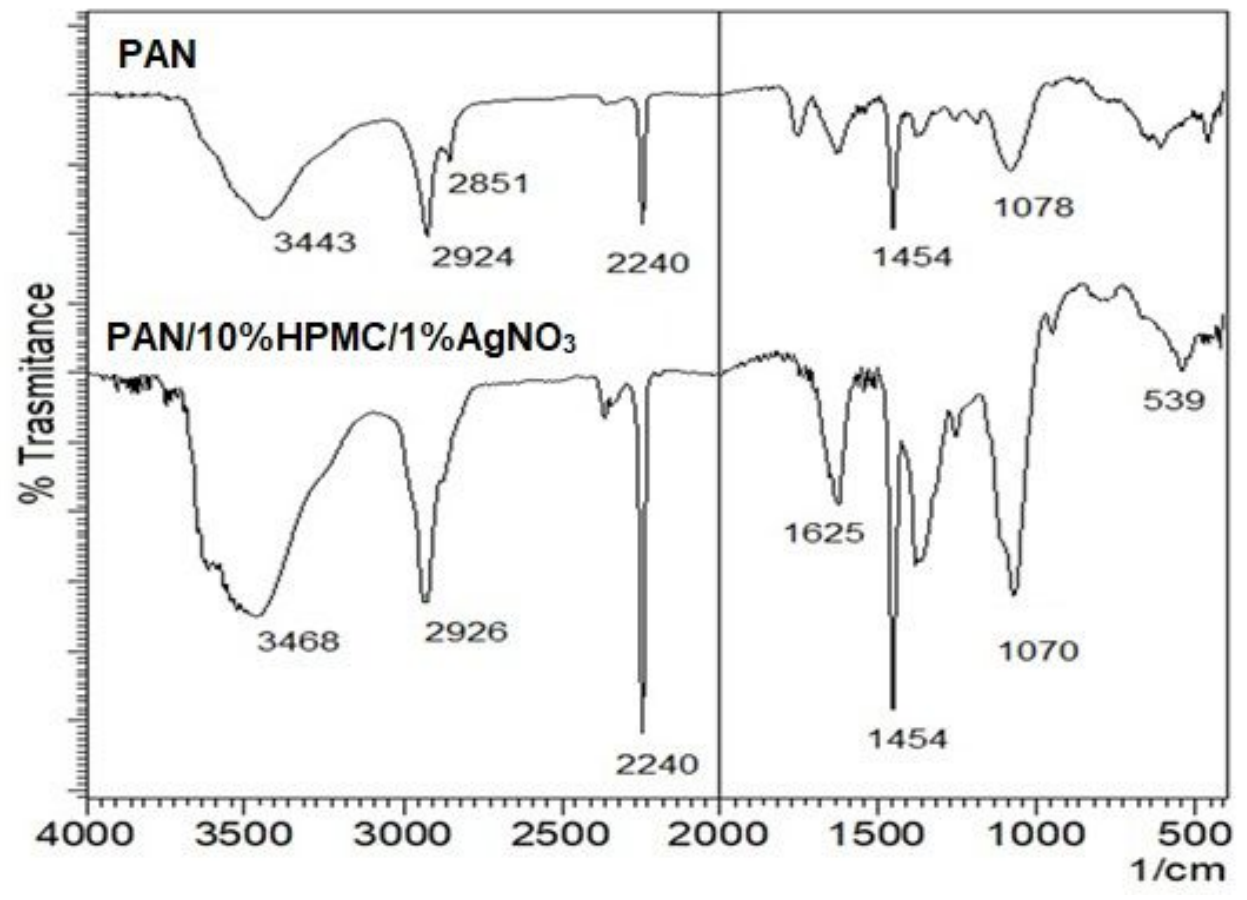


Figure 4

Infrared spectra of PAN and PAN/10\%HPMC/1\%AgNO3 nanostructured membranes

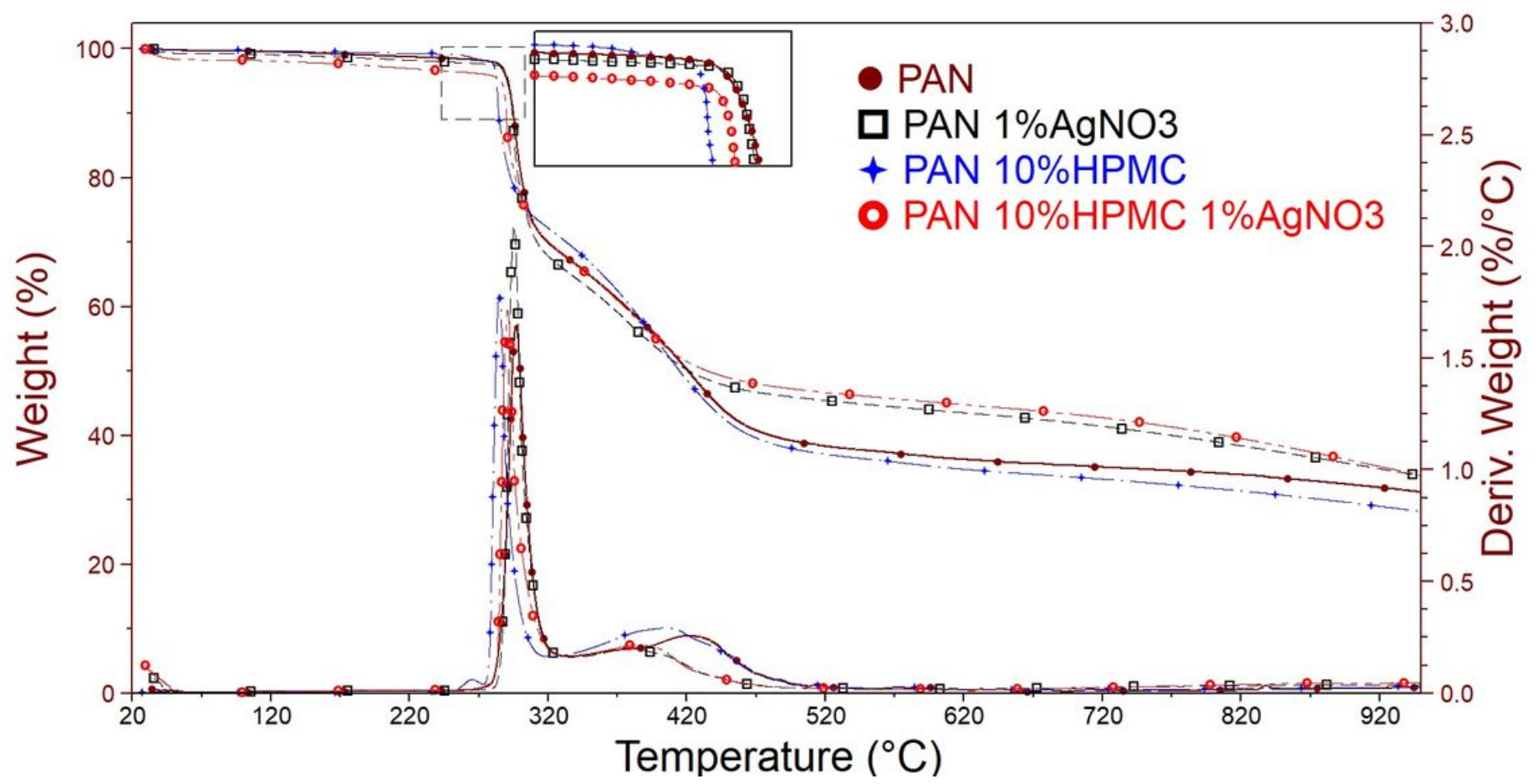

Figure 5

TGA/DTG analysis of PAN, PAN/1\%AgNO3, PAN/10\%HPMC and PAN/10\%HPMC/1\%AgNO3 nanostructured membranes

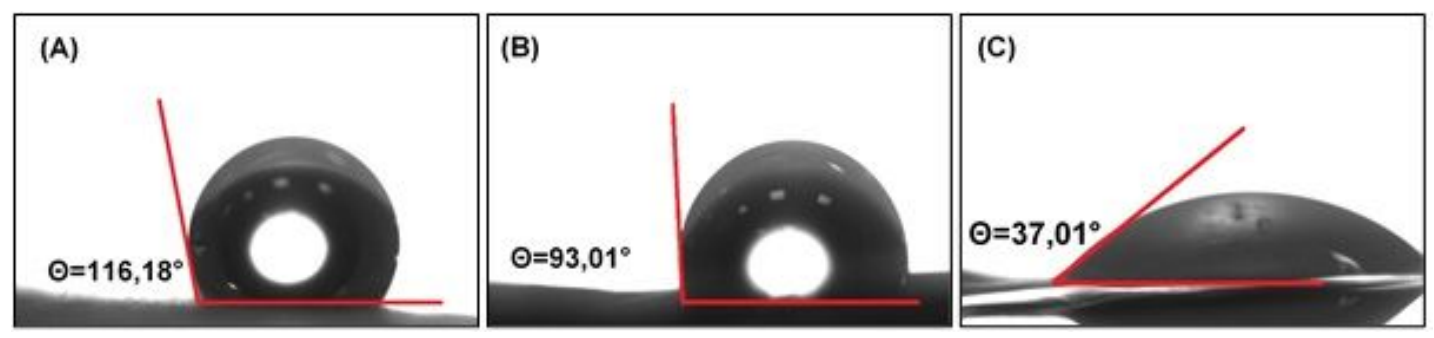

\section{Figure 6}

Images of contact angle concerning nanostructured membranes: (A) PAN, (B) PAN/0.5\%AgNO3, (C) PAN/1\%AgNO3 


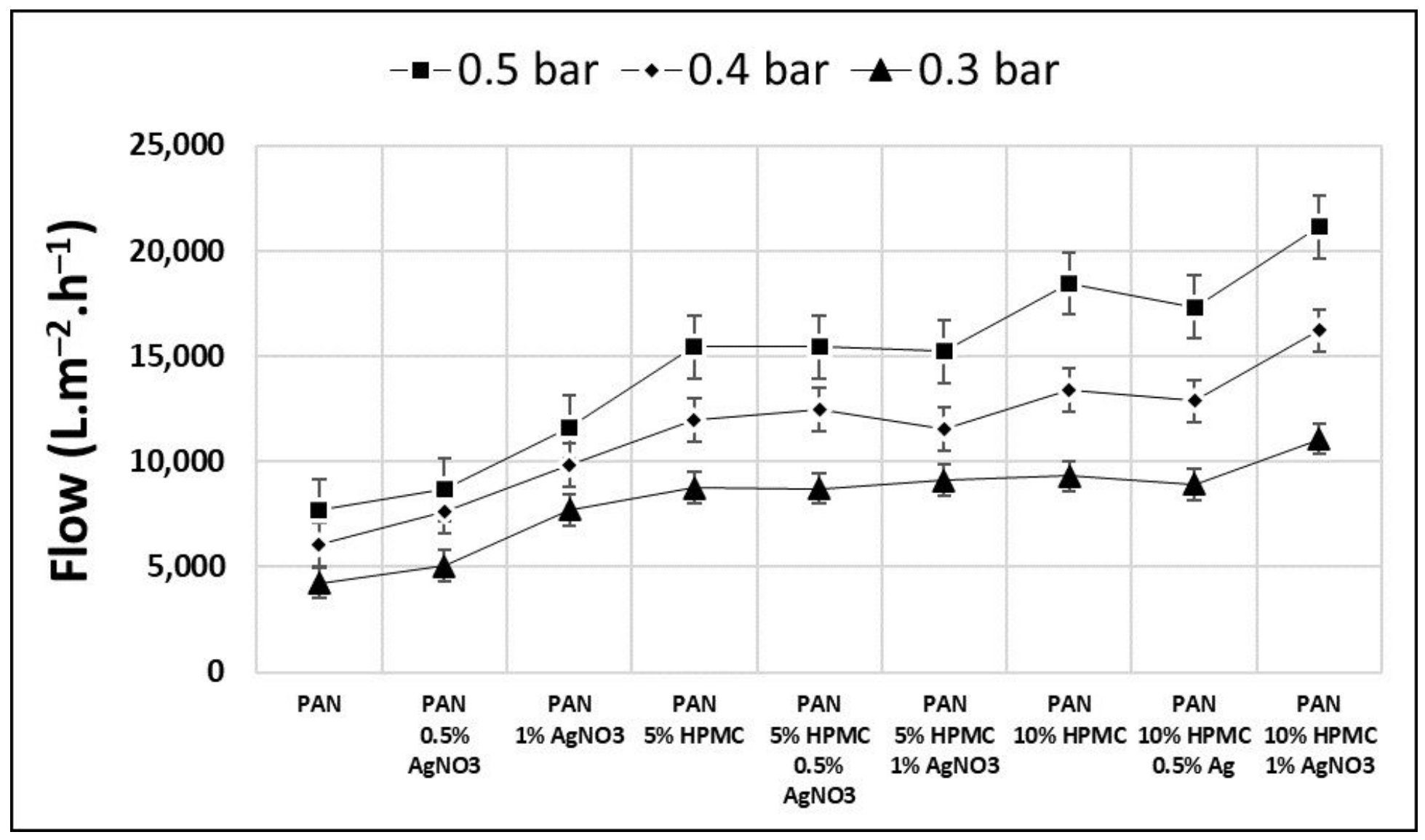

Figure 7

Permeability of nanostructured filtering membranes
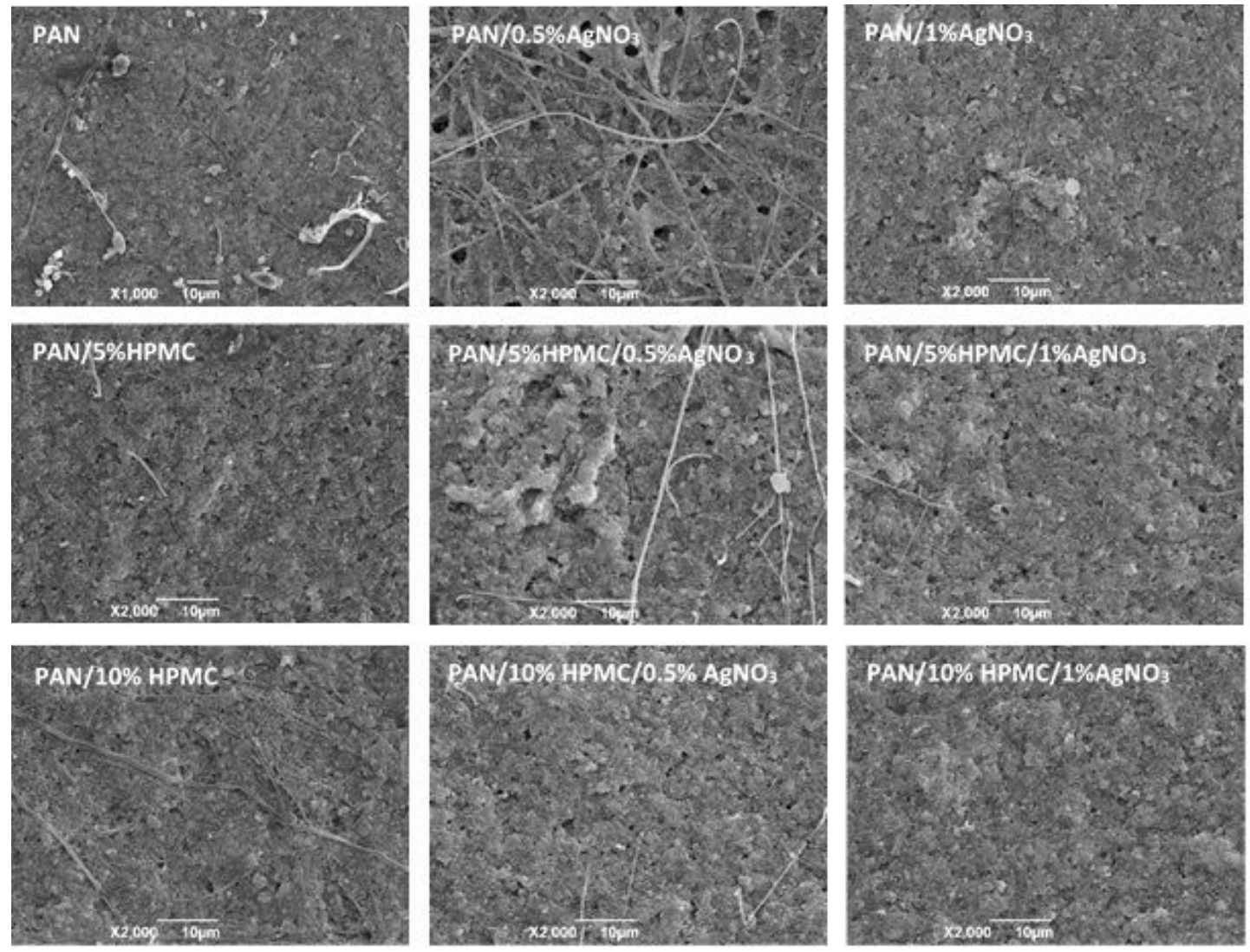


\section{Figure 8}

SEM images of nanostructured membranes after bauxite effluent filtration
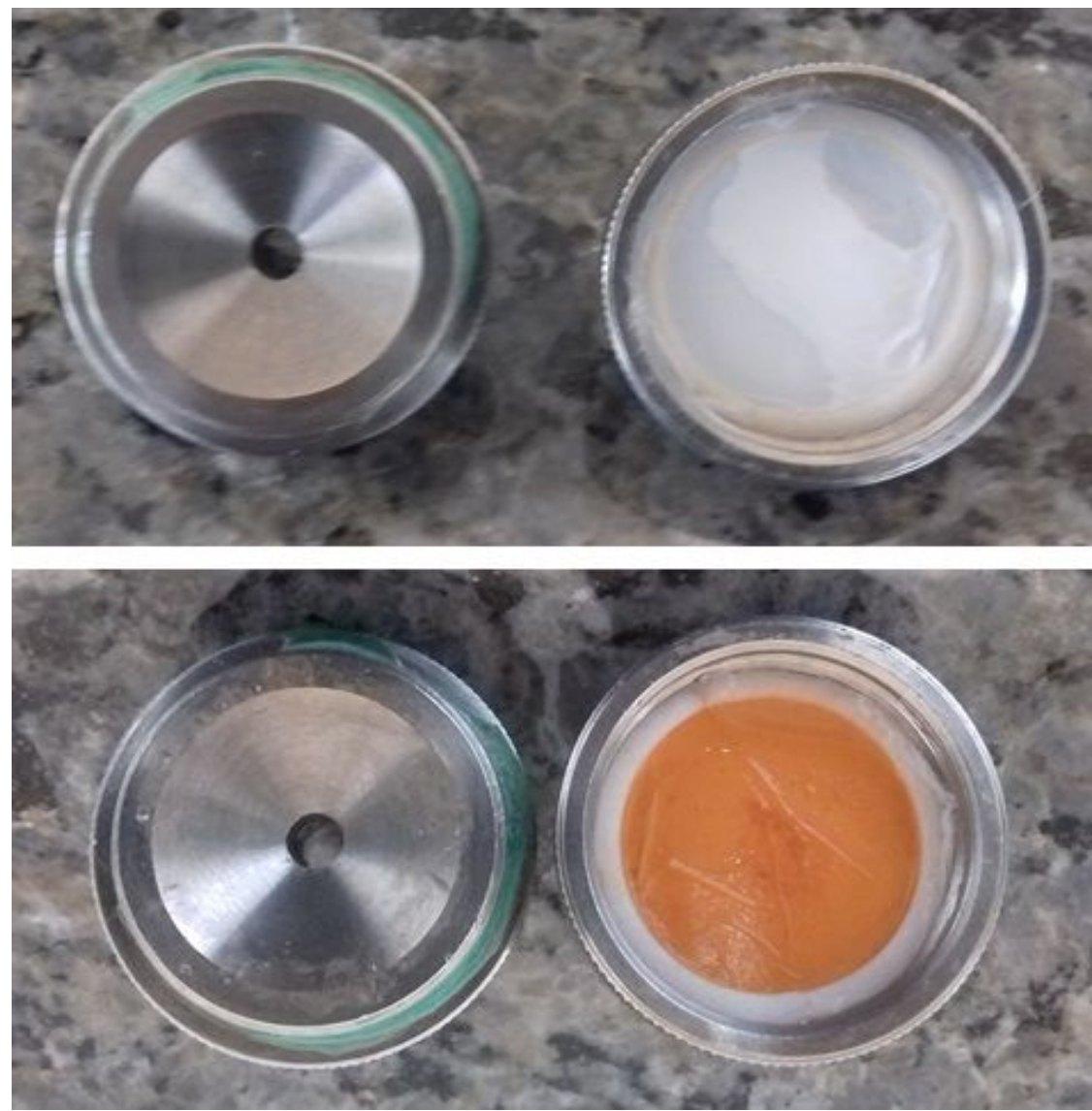

\section{Figure 9}

Before and after images concerning nanostructured filtering membranes use for bauxite wastewater treatment 


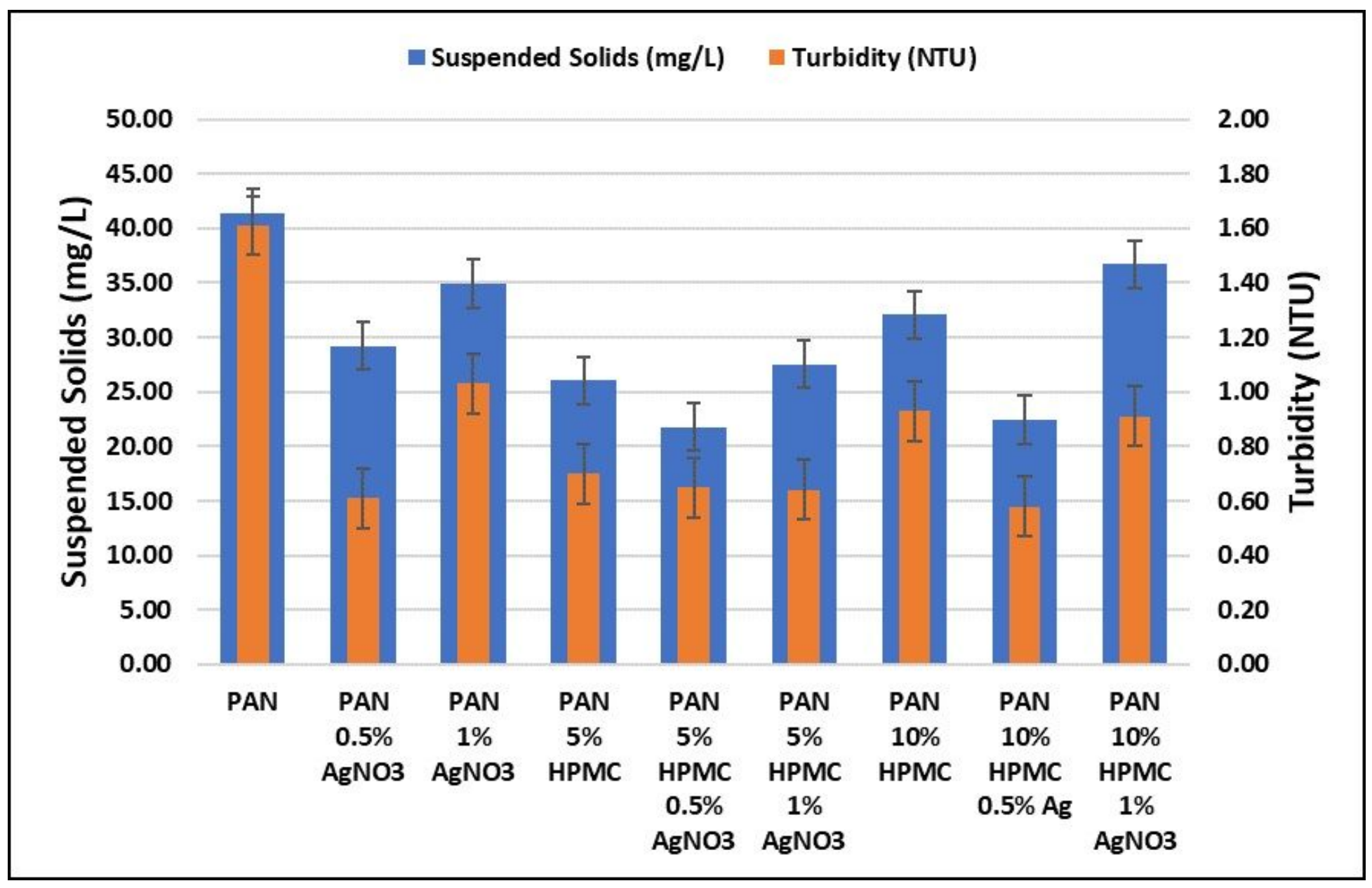

Figure 10

Relationship between turbidity and suspended solids after filtration

\section{Supplementary Files}

This is a list of supplementary files associated with this preprint. Click to download.

- FigSI1.tif

- Tablesı1.docx 